\title{
Endodontic Treatment of Mandibular First Premolar Having Bifurcated Canals at Apical Third Level- Case Reports
}

\author{
Dr. Dnyaneshwar S. Patil \\ MDS, Dept of Conservative Dentistry \& Endodontics (India)
}

\begin{abstract}
Mandibular premolars are oftenly considered as enigma to the endodontist. The mandibular premolars have high flare-up and highest failure rates because of extreme variations in root canal morphology. The clinicians should be aware of the presence of anatomical variations in the teeth during endodontic treatment. The aim of this case report is to describe the diagnosis and treatment of the cases of mandibular premolars with single root with bifurcating canals at apical third level.
\end{abstract}

Keywords: endodontic, mandibular premolar, bifurcation

\section{Introduction}

For a successful root canal treatment meticulous cleaning, shaping and filling of the root canal system three dimensionally are primary requisites ${ }^{[1]}$. It's proved beyond doubt that root canal system is highly complex, intricate and variable. The knowledge and attention to typical and atypical anatomy can be a critical factor in determining the success of endodontic therapy. The anatomic studies reported on the prevalence of number of roots and root canals in mandibular second premolars are limited. Anatomic studies have reported a single root in $99.6 \%$ of these teeth. Two roots were found in $0.3 \%$ of these teeth. Three roots were found in only $0.1 \%$ of mandibular second premolars. ${ }^{[1,2]}$

Slowey ${ }^{[3]}$ has suggested that the mandibular premolars may present the greatest difficulty of all teeth to perform successful endodontic treatment. A study at the University of Washington in 1955 assessed the failure rate of non-surgical root canal treatment in all teeth ${ }^{[4]}$. The mandibular first premolar had the highest failure rate in the study at $11.45 \%^{[4,5]}$. Possible reasons for this conclusion are the numerous variations in root canal morphology and difficult access to additional canal systems when present.

This article will discuss the clinical management of mandibular premolars bifurcated canal.

\section{Case I}

A 42 year old male patient, reported with the chief complaint of pain in the lower right back region of the jaw since past 1 month. On further questioning the patient revealed that the pain was dull aching and intermittent in nature. The pain aggravated during mastication after which it lingered for about 2-5 minutes. The past medical and dental history of the patient was non contributory. On clinical examination of area of chief complaint showed deep occlusal carious lesion with 44 and deep abrasion cavity was present with 45 . Radiograph showed deep disto-occlusal carious lesion with $1^{\text {st }}$ premolar.[Fig, 1]. Radiograph showed that single rooted premolar with single canal clearly visible till junction of middle and apical third of root, which suspected presence of furcating canal. Diagnosis of symptomatic irreversible pulpitis was established with both the teeth and root canal treatment was planned.

Local anaesthesia was induced using $1.8 \mathrm{ml} 2 \%$ lidocaine with 1: 200,000 epinephrine (Xylocaine, AstraZeneca Pharma India Ltd, Bangalore, India). Conventional endodontic access opening was established with an Endo Access Bur (Dentsply Tulsa, Tulsa, OK). An ovoid shaped opening was seen at the center. No 10 $\mathrm{K}$ file was inserted which showed bifurcation at apical third with 44 . Working lengths were estimated by using an electronic apex locator (iPEX II, NSK) and then confirmed with a radiograph.[ Fig. 2]. Further cleaning and shaping was carried out with protaper rotary instruments (Dentsply-Maillefer, Switzerland) copious irrigation with 3\% sodium hypochlorite. After preparation, the root canals were inserted with gutta-percha cones (Diadent, Seoul, Korea) to reconfirm working lengths. Post obturation an angled radiograph showed separate gutta percha cones till full working length.[Fig. 3] The patient experienced no post-treatment pain or discomfort and post endodontic restoration was done subsequently.

\section{Case II}

A 45 years female patient came with the chief complaint of pain in lower left back region of jaw since 15days. Patient gave a history of night pain in the given region since 2 days. On clinical examination deep carious lesion was seen with 34 and 35, and pain on percussion was found with 35 . Electric pulp test gave no response with 35 and exaggerrated response with 34. Radiographic Examination showed deep carious lesions almost involving pulp space[Fig.4]. Diagnosis of pulp necrosis with acute apical periodontitis was made with 
35 and symptomatic irreversible pulpitis with 34 and endodontic treatment for both the teeth was discussed with patient and scheduled.

After profound anaesthesia, standard endodontic access was made. Single separate canal with 35 and single canal that bifurcated at apical third was found with 34. Standard procedure as mentioned above was followed to complete the root canal treatment.["Fig.5,6 \& 7"].

\section{Figures}

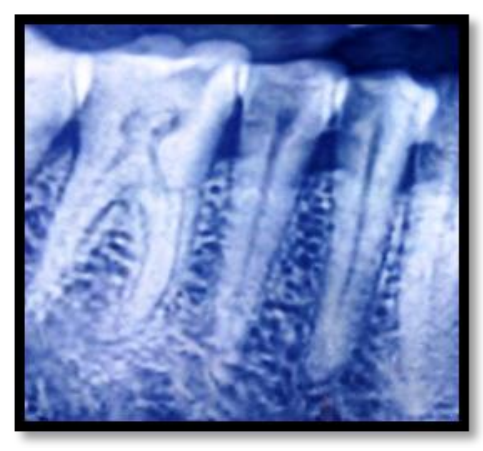

Fig. 1

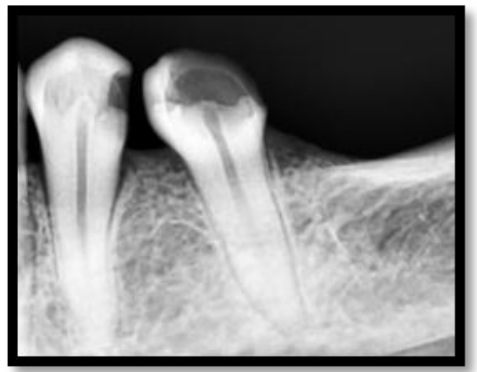

Fig. 4

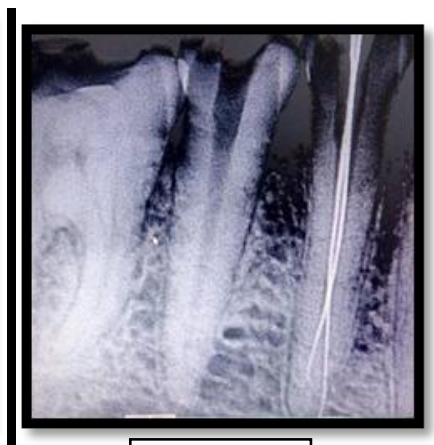

Fig. 2

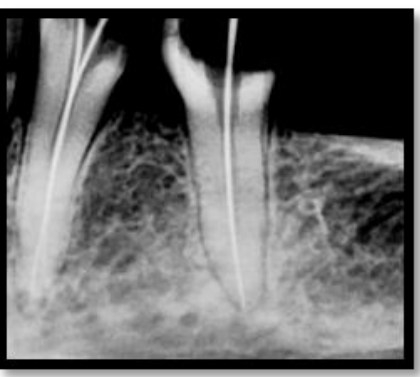

Fig. 5

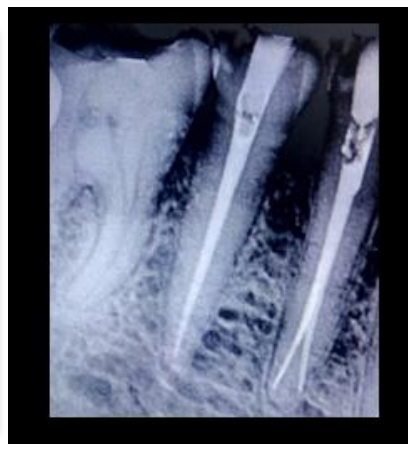

Fig. 3

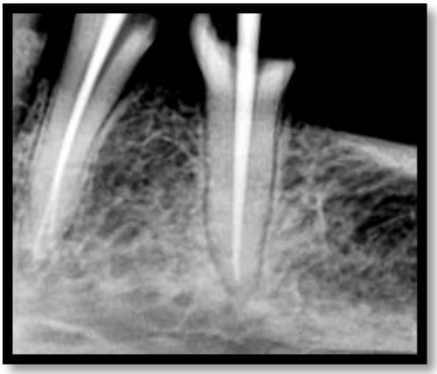

Fig. 6

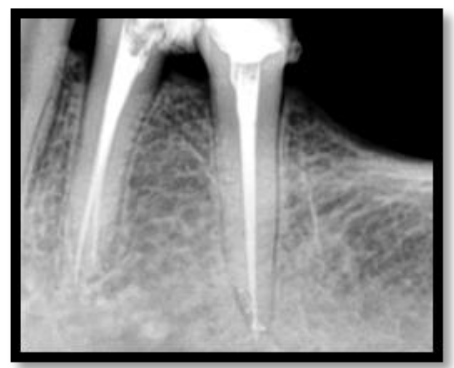

Fig. 7

\section{Discussion}

Anatomical variations, especially extra canals and roots, should always be kept in mind when treating teeth endodontically. Failure of root canal treatment is related to the presence of bacterial biofilm in the root canal system ${ }^{[6]}$. A missed canal or an unclean root canal system can be a cause for treatment failure.

Brescia considered that morphology of mandibular premolar was the most variable in the entire dentition. Vertucci (1978) reported that mandibular premolars have Type I canal in $70 \%$ of the cases, Type II canal in $4 \%$ of the cases, Type III canal in $1.5 \%$ of the cases and Type IV canal in $24 \%$ of the cases ${ }^{[1]}$. Hence, it is recommended that clinicians should consider a thorough assessment of radiographs. The crucial step in 
finding the split canal was tactile examination of main canal with a small, precurved K-file tip ${ }^{[7]}$. After locating the canals, access was widened to facilitate root canal preparation.

The detection of additional root canals requires a careful clinical and radiographic inspection. Diagnostic tools such as multiple radiographs, careful examination of the pulpal floor with a sharp explorer, and better visualization using an operating microscope are all important aids in the detection of additional root canals. Recently, various attempts have been made to use CBCT imaging for the confirmatory diagnosis of morphologic aberrations in the endodontic field.

\section{Conclusion}

Clinician should be aware of variations related to canal configuration and types in mandibular first premolars. Tactile examination is a key step in locating the extra/split canal. Three-dimensional obturation not only seals the apical third but also seals multiple portals of exit, that is, the accessory canals and furcal canals.

\section{References}

[1]. Vertucci FJ. Root canal anatomy of the human permanent teeth. Oral Surg Oral Med Oral Pathol 1984, 58,589-599.

[2]. Cleghorn BM, Christie WH, Dong CC. The root and root canal morphology of the human mandibular second premolar: a literature review. J Endod 2007;33:1031-1037.

[3]. Slowey RR. Root canal anatomy. Road map to successful endodontics. Dent Clin North Am 1979;23:555-73.

[4]. Ingle J, Bakland L. Endodontics, 5th ed. Hamilton: BC Decker, 2002.

[5]. England MC Jr, Hartwell GR, Lance JR. Detection and treatment of multiple canals in mandibular premolars. J Endod 1991;17:174-8.

[6]. Ricucci D, Siqueira JF Jr, Bate AL, Pitt Ford TR. Histologic investigation of root canaltreated teeth with apical periodontitis: a retrospective study from twenty-four patients. J Endod 2009;35:493-502.

[7]. N. P. Gupta, R. Bansal, and M. Bansal, "Treatment of mandibular first premolar with type IV root canal: a case report," Indian Journal of Dental Sciences, vol. 2, no. 2, pp. 26-27, 2010. 